Research Article

\title{
Model Test and Back Analysis of Shield Tunnel Load Distribution in Soft Clay
}

\author{
Haoshuang Niu, Xiaolin Weng ${ }^{D}$, Chao Tian, and Deng Wang \\ Key Laboratory for Special Area Highway Engineering of Ministry of Education, Chang'an University, Xi'an 710064, China \\ Correspondence should be addressed to Xiaolin Weng; wengxl2000@126.com
}

Received 17 March 2021; Accepted 30 April 2021; Published 27 May 2021

Academic Editor: Xianjie Hao

Copyright (c) 2021 Haoshuang Niu et al. This is an open access article distributed under the Creative Commons Attribution License, which permits unrestricted use, distribution, and reproduction in any medium, provided the original work is properly cited.

\begin{abstract}
Combined with the soft clay layer of Foshan metro, a back-analysis method combining model test and numerical simulation is developed. First, the similitude criterion for the model used in this study was derived from similarity theory and elasticity mechanics equations. Artificial clay is prepared by mixing kaolin, bentonite, loess, and river sand in proportions of $4: 2: 3: 1$. Gypsum, water, and borax are mixed in proportions of $1: 0.7: 0.015$ to simulate the tunnel lining. The model tests were carried out based on four load modes: the combination of mode 1, vertical load distribution and horizontal load linear distribution, mode 2 , vertical load distribution and horizontal load parabolic distribution, mode 3, vertical load parabolic distribution and horizontal load linear distribution, and mode 4, vertical and horizontal load parabolic distribution. Then, the calculation model corresponding to the four load modes is established using ABAQUS, and the measured data is back-analyzed as the known quantity. The specific load values obtained were $359 \mathrm{kPa}, 380 \mathrm{kPa}, 361 \mathrm{kPa}$, and $368 \mathrm{kPa}$ by the load-internal force curve. The bending moment and axial force are calculated by substituting the back-analysis load values back into the model and comparing the results with the measured values; it was found that the internal forces under the back-calculation load still deviated by varying degrees. By using the comprehensive error function $E$ to evaluate the advantages and disadvantages of the four distribution modes, the comprehensive errors are 4.3\%, 1.7\%, 6.5\%, and 5.9\%, respectively. That is, the error of load distribution of mode 2 (the combination of vertical load distribution and horizontal load parabolic distribution) is the lowest and is highly consistent with the measured value, which is the closest to the characteristics of the load pattern of the stratum.
\end{abstract}

\section{Introduction}

Driven by the strong economic development of China, the urbanization process has continued to grow, especially in coastal cities. With increasing population densities, traffic problems have gradually emerged. The construction of urban subways can relieve traffic pressure and improve productivity. Efficiency promotes urban economic development and further accelerates the pace of modernization [1-3]. Since 2012, approximately 3 trillion RMB has been invested in China's urban rail transit system, and this number is expected to exceed 500 billion RMB this year. Rail transit construction can be divided into civil engineering construction and mechanical-electrical equipment construction, primarily including locomotive purchase and signal system construction, of which civil engineering costs account for $70 \%$ of the total subway construction costs. For example, Beijing Metro Line 4 represents a construction investment of 15.4 billion RMB, of which 10.7 billion RMB is slated for the construction of civil engineering projects, and the cost of the subway segment accounts for $40 \%$ of the total cost $[4,5]$. Therefore, how to simplify segment design and reduce material costs has become a pressing issue in current research and how to determine the distribution law of water and soil pressure around segments and the size of external loads has become the first crucial link in accomplishing material reductions.

The existing theoretical calculation methods usually idealize the water-soil load on the upper part of a segment into a uniformly distributed load at infinite distance and regard the horizontal load as having a linear distribution. 
The primary problem is that the model itself is only an assumed distribution form, which cannot reflect the actual conditions experienced by the tunnel lining under the action of many influencing factors. Research regarding water-soil pressure under an external load acting on the lining is divided into water-soil separation algorithms and water-soil combination algorithms [6-9]. Among them, the study of earth pressure is mainly based on a simplified calculation method. In this method, the earth pressure acting on the lining is generally divided into four parts: vertical formation pressure, horizontal formation pressure, vertical foundation reaction force at the arch bottom, and passive elastic resistance. Soil column theory and Terzaghi theory ignore the influence of the soil arching effect on vertical pressure in vertical formation pressure calculations, while Platt's theory only considers the soil arching effect without considering its own limitations; in some loose soil layers or tunnels at shallow depth, it is impossible to form a stratigraphic arch effect. At the same time, many scholars have carried out a series of research studies on the earth-induced pressure by applying a calculation method to determine the interaction between the stratum and the lining [10-16]. To study the water pressure effect, papers $[17,18]$ carried out a comprehensive and systematic analysis of the water pressure of shallow tunnels combined with a large number of numerical simulation results in the early 21 st century and finally solved the problem of water pressure distribution. Reference [19] provided a comprehensive and detailed description of the water pressure borne by the underwater lining structure based on certain theory and many years of practical experience. Reference [20] proposed a method to determine the size and distribution of water pressure under special geological conditions and external loads based on tunnel engineering in seismic areas. In domestic tunnel design studies, most of the analytical calculations of the lining water load are based on the specification for design of hydraulic tunnel SL279-2002 and related research experience.

Owing to regional differences, it is difficult to use the theoretical method and numerical calculations as the unified calculation standard to determine the external load action mode. Therefore, models that describe the external load action mode of tunnels at home and abroad are not perfect. At present, numerical simulation is the main research method [21-26], but it is affected by deviations in formation parameters such that the results are not always satisfactory or practical. The most accurate data can only be obtained through field tests. However, owing to environmental factors and economic conditions, the field test method is limited to only a few major projects. Therefore, the small sample size and relatively large dispersion make it difficult to produce accurate models [27-30].

The underground engineering construction in the Foshan area is taking place in the offshore sedimentary clay layer, and the stratum soil is mostly soft clay with high water content, which creates significant problems regarding the structural design and construction of the project, such as water gushing from an excavation face, the segment floating, and mud caking in shield props. In this special case, from the perspective of engineering safety and construction stability, determining the distribution of water and soil pressure around the segment is particularly important. In this paper, taking Foshan Metro Line 2 (Green Island Lake-Liantang) as the engineering background [31-33], with the aid of model tests to simulate the actual conditions of the prototype, and through the comprehensive evaluation of the measured data and the finite element calculations, four distribution modes of the shield lining external load in the water-rich soft clay area are assumed and evaluated by applying a back calculation. Finally, the lining load model most suitable for the geological conditions of the Foshan stratum is proposed. To provide a new research idea for determining the lining load under different geological conditions, the research followed in support of this paper is shown in Figure 1.

\section{Experimental Design}

2.1. Similarity Relationship. According to the three fundamental laws of the similarity theorem and the results of an analogous modeling test $[34,35]$, the ratio of similitude $(C)$ can be deduced by means of equation analysis to satisfy the similarity relationship. Considering the surrounding rock as homogeneous, continuous, and isotropic material and taking only the self-weight stress into account, the satisfaction relationships are expressed as follows:

$$
\left\{\begin{array}{l}
\frac{\partial\left(\sigma_{x}\right)_{j}}{\partial_{x j}}+\frac{\partial\left(\tau_{x y}\right)_{j}}{\partial_{y j}}+\frac{\partial\left(\tau_{x z}\right)_{j}}{\partial_{z j}}=0, \\
\frac{\partial\left(\tau_{y z}\right)_{j}}{\partial_{x j}}+\frac{\partial\left(\sigma_{y}\right)_{j}}{\partial_{y j}}+\frac{\partial\left(\tau_{y z}\right)_{j}}{\partial_{z j}}=0, \\
\frac{\partial\left(\tau_{x z}\right)_{j}}{\partial_{x j}}+\frac{\partial\left(\tau_{y z}\right)_{j}}{\partial_{y j}}+\frac{\partial\left(\sigma_{z}\right)_{j}}{\partial_{z j}}-\gamma_{j}=0, m, \\
C_{\sigma}=\frac{\left(\sigma_{x}\right)_{s}}{\left(\sigma_{x}\right)_{m}}=\frac{\left(\sigma_{y}\right)_{s}}{\left(\sigma_{y}\right)_{m}}=\frac{\left(\sigma_{z}\right)_{s}}{\left(\sigma_{z}\right)_{m}} \\
C_{\sigma}=\frac{\left(\tau_{x y}\right)_{s}}{\left(\tau_{x y}\right)_{m}}=\frac{\left(\tau_{y z}\right)_{s}}{\left(\tau_{y z}\right)_{m}}=\frac{\left(\tau_{z x}\right)_{s}}{\left(\tau_{z x}\right)_{m}} \\
C_{E}=\frac{E_{s}}{E_{m}}, C_{\mu}=\frac{\mu_{s}}{\mu_{m}}, C_{\gamma}=\frac{\gamma_{s}}{\gamma_{m}} \ldots \\
C_{L}=\frac{x_{s}}{x_{m}}=\frac{y_{s}}{y_{m}}=\frac{u_{s}}{u_{m}}=\frac{l_{s}}{l_{m}},
\end{array}\right.
$$

By substituting $C_{\sigma}, C_{L}, C_{\varepsilon}, C_{\delta}, C_{E}, C_{\mu}$, and $C_{\gamma}$ into the above equation and comparing the equation of the prototype/model, the following equation can be obtained: 


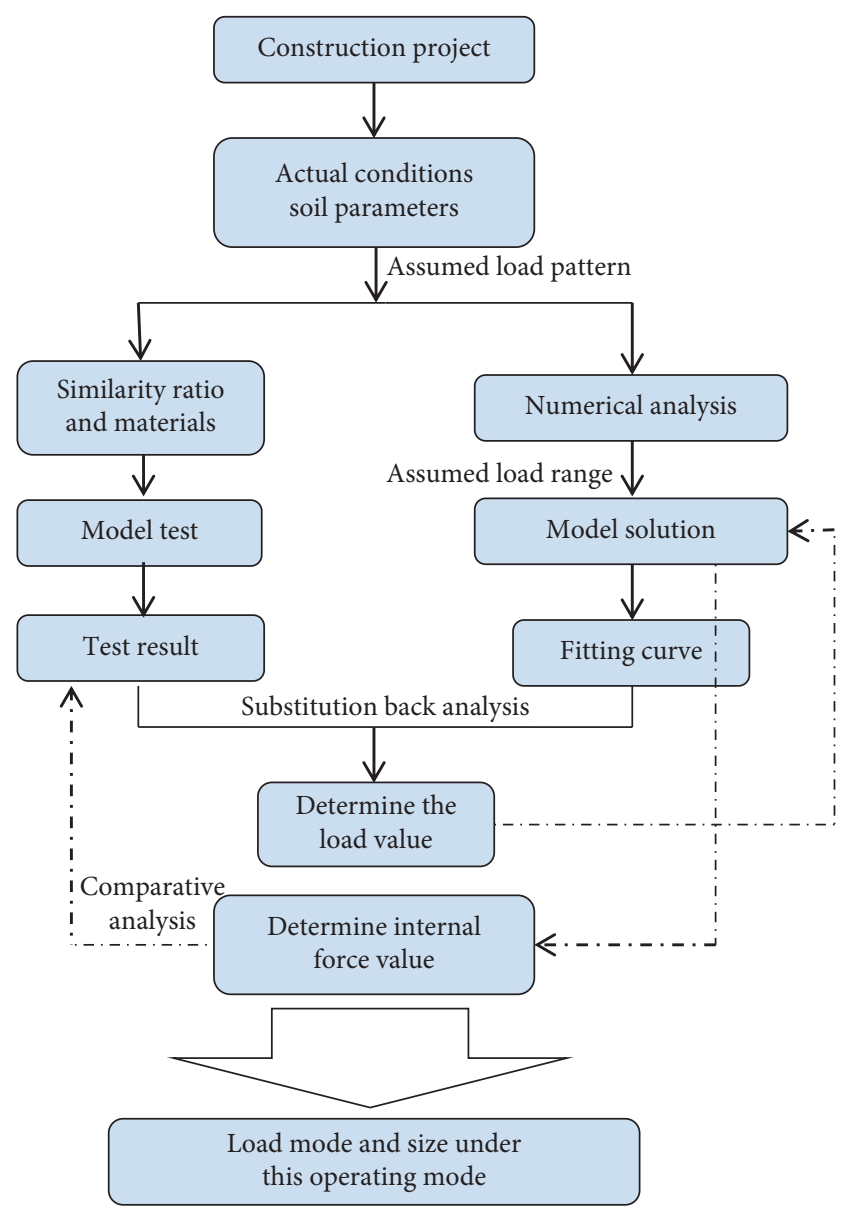

Figure 1: Outline of the research route followed in this paper.

$$
\left\{\begin{array}{l}
\frac{C_{\gamma} C_{L}}{C_{\sigma}}=1, \frac{C_{\varepsilon} C_{L}}{C_{\delta}}=1, \\
\frac{C_{\sigma}}{C_{\varepsilon} C_{E}}=1, C_{\mu}=1 .
\end{array}\right.
$$

The relevant physical quantities used in this test are stress $(\sigma)$, strain $(\varepsilon)$, load $(P)$, displacement $(\delta)$, elastic modulus $(E)$, Poisson's ratio $(\mu)$, density $(\gamma)$, moisture content $(w)$, and length $(L)$. From the expression $f(\sigma, \varepsilon, P, \delta, E, \mu, \gamma, w$, $L)=0$,

$$
\begin{aligned}
& \pi_{1}=\frac{\sigma}{P}, \pi_{2}=\frac{L \gamma}{P}, \pi_{3}=\frac{E}{P}, \pi_{4}=\frac{\mu}{P}, \pi_{5}=\mu, \pi_{6}=w, \pi_{7}=\varepsilon \\
& \left\{\begin{array}{l}
\frac{C_{\gamma} C_{L}}{C_{\sigma}}=1, \frac{C_{\varepsilon} C_{L}}{C_{\delta}}=1, \frac{C_{\sigma}}{C_{\varepsilon} C_{E}}=1, \frac{C_{P}}{C_{E}}=1, \\
C_{\mu}=C_{w}=C_{\varepsilon}=C_{\varphi}=1 .
\end{array}\right.
\end{aligned}
$$

The similarity ratios are then expressed as below.
2.2. Similarity Parameters. Considering the experimental conditions, the selected geometry and volume-weight similarity ratios are $30: 1$ and $1: 1$, respectively. That is, $C_{L}=30$ and $C_{\gamma}=1$. Consequently, the other similarity parameters can be determined, as shown in Table 1 .

2.3. Similarity Material. Because a mixture of artificial materials has been proven to be appropriate for a scaled model test, model material for soft clay is developed in this study to satisfy the requirements of the scaled test [36]. The similarity material involves two mixture ratio tests: the soft clay and lining. As shown in Figure 2, based on the analysis of the plastic state and permeability of the soil, the soft clay material is simulated by using a combination of kaolin, bentonite, loess, and river sand [37, 38]. Mix ratios of GPHS1 $(4: 2: 3: 1)$ and GPHS2 $(3: 2: 4: 1)$ are used in the tests. Finally, the GPHS1 ratio was used to simulate the soft clay layer of Foshan Metro Line 2. Through a set of compressive strength cube tests conducted on cubes consisting of different ratios, the one closest to the similarity criterion for the tunnel lining is identified as the gypsum: water $=1: 0.7$ and water: borax $=1: 0.015$ mixture ratio. Borax makes the mixture more closely approximate the tunnel lining material [39]. Similar materials are shown in Table 2. The reinforcement calculation shows that the similar material for the main reinforcement is single-layer no. 20 wire mesh with $D=0.6 \mathrm{~mm}$ and hole spacing of $10 \mathrm{~mm}$.

2.4. Experimental Model and Devices. As shown in Figure 3, the mold, whose size is set according to the similar proportions used, is composed of an internal template, external template, fixed support, and single-layer reinforcing mesh. The mixed material is mixed in the proportions determined by the test results and is then poured into the installed mold to create the tunnel model, as shown in Figure 3. Gypsum pipe with $\Phi$ $200 \mathrm{~mm} \times 10 \mathrm{~mm}$ is used as the shield tunnel lining. All tests were conducted within a self-designed test chamber (see Figure 4), whose dimensions are $180 \mathrm{~cm} \times 160 \mathrm{~cm} \times 60 \mathrm{~cm}$, and $1.0 \mathrm{~cm}$ thick toughened glass is used in the inner wall to minimize the boundary effect.

2.5. Experimental Conditions and Tests. The data to be collected in the test mainly include the earth pressure, lining bending moment, and the axial force acting on the segment. The lining earth pressure 0065 is measured by eight miniature earth pressure boxes (P-1-P-8) uniformly arranged around the lining of the model, with sensitivity $=0.1 \%$ F.S. The location of the moment and axial force is the same as that of the earth pressure, and it is indirectly measured by eight strain gauges (resistance $=120.0 \pm 0.3 \Omega$, sensitivity coefficient $=2.08 \pm 0.01$ ) inside and outside the model lining. The layout of the test elements is shown in Figure 5, and the monitoring system is shown in Figure 6. 
TABLe 1: Similarity parameters of model test.

\begin{tabular}{lccc}
\hline Physical indexes & Dimension & Similarity relationship & Similarity ratio \\
\hline Geometry & $L$ & $C_{L}$ & 30 \\
Load & $F L^{-2}$ & $C_{P}=C_{L}$ & 30 \\
Stress & $F L^{-2}$ & $C_{\sigma}=C_{F}$ & 30 \\
Elastic modulus & $F L^{-2}$ & $C_{E}=C_{P}$ & 30 \\
Displacement & $L$ & $C_{\delta}$ & 30 \\
Poisson ratio & 1 & $C_{\mu}$ & 1 \\
Water content & 1 & $C_{w}$ & 1 \\
Volume-weight & $F L^{-3}$ & $C_{\gamma}$ & 1 \\
Strain & 1 & $C_{\varepsilon}$ & 1 \\
\hline
\end{tabular}

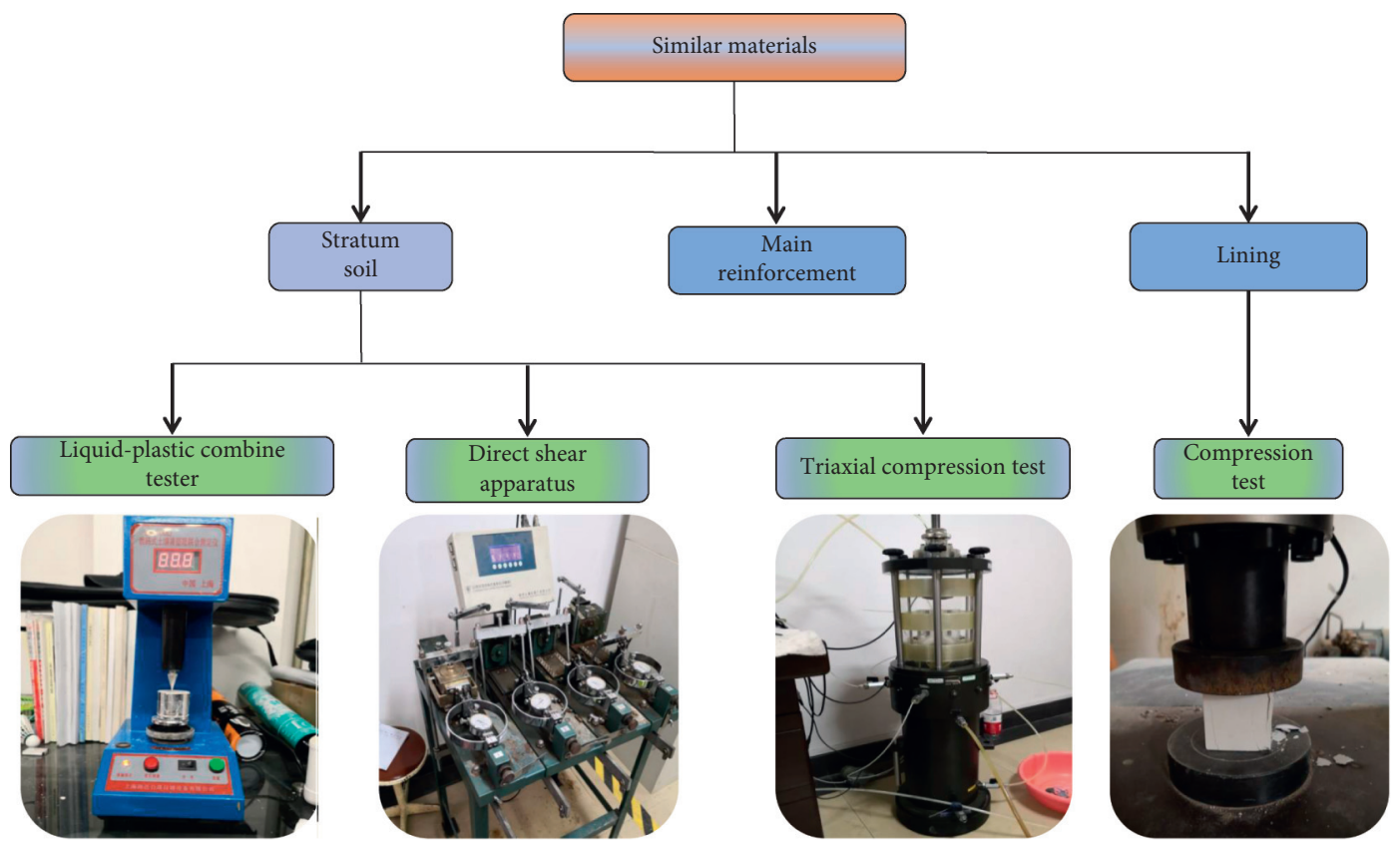

FIgURE 2: Equipment for optimization tests of similar material parameters.

TABle 2: Prototype and model materials.

\begin{tabular}{lc}
\hline Prototype material & Model material \\
\hline Soft clay & Kaolin: bentonite: loess: sand $=4: 2: 3: 1$ \\
Tunnel lining & Water: gypsum $=0.7: 1$, borax accounts for $1.5 \%$ of water \\
Main reinforcement & $n=20, d=0.6 \mathrm{~mm}$, and pitch $=10 \mathrm{~mm}$ \\
\hline
\end{tabular}

The bending moment and axial force of the tunnel model can be determined from the following formula through the strain gauges on the internal and external surfaces: $M=E$ $\left(\varepsilon_{A}-\varepsilon_{B}\right) b h^{2} / 12, N=E\left(\varepsilon_{A}+\varepsilon_{B}\right) b h / 2$, where $\varepsilon_{B}$ is the internal surface strain of the lining, $\varepsilon_{A}$ is the external surface strain of the lining, $b$ is the unit length, $h$ is the lining thickness, and $E$ is the elastic modulus of the lining.

\subsection{Experimental Procedure}

Step 1. The model test chamber is constructed (see Figure 4), and plastic film is pasted onto its inner wall and then coated with an oil layer to reduce the friction between the chamber and the surrounding soil.
Step 2. The tunnel is constructed according to the similarity ratio calculated by similarity theory; similar materials are weighed according to the proportions being tested, are mixed evenly in a mixer, and then are poured into a highprecision abrasive mixer and are vibrated until they are compacted.

Step 3. After the model box is ready, the bottom is filled with the similar material to a height of $0.28 \mathrm{~m}$, which is then compacted to prevent any uneven stresses in the model from interfering with the monitoring instruments, which would otherwise affect the soil displacement around the tunnel and cause data abnormalities. 


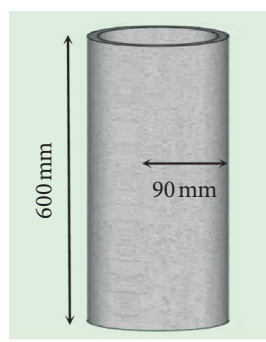

(a)

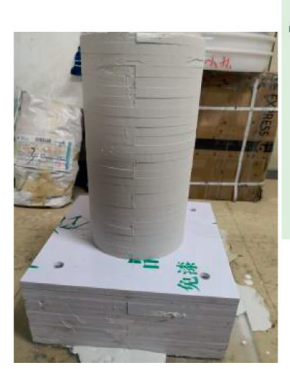

(c)

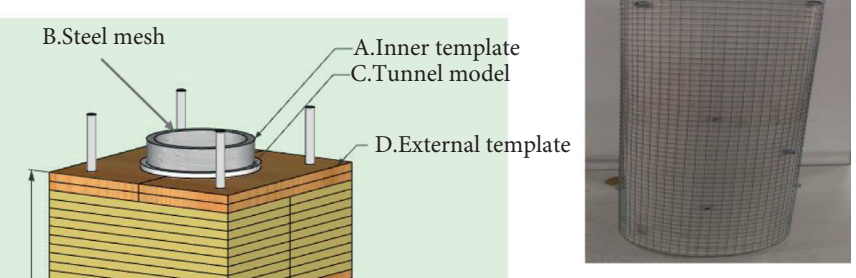

(b)

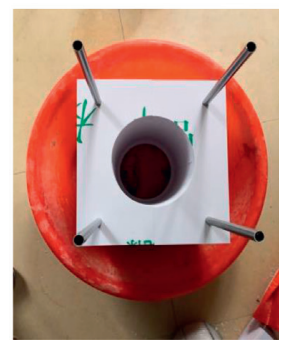

(d)

FIGURE 3: Model of tunnel lining structure.

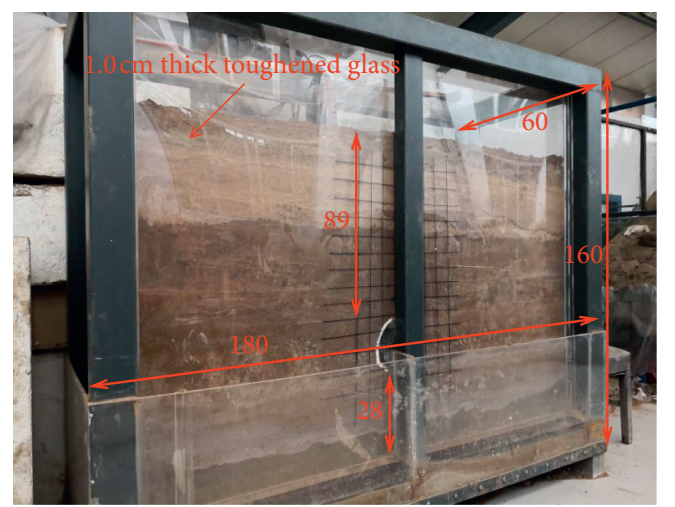

(a)

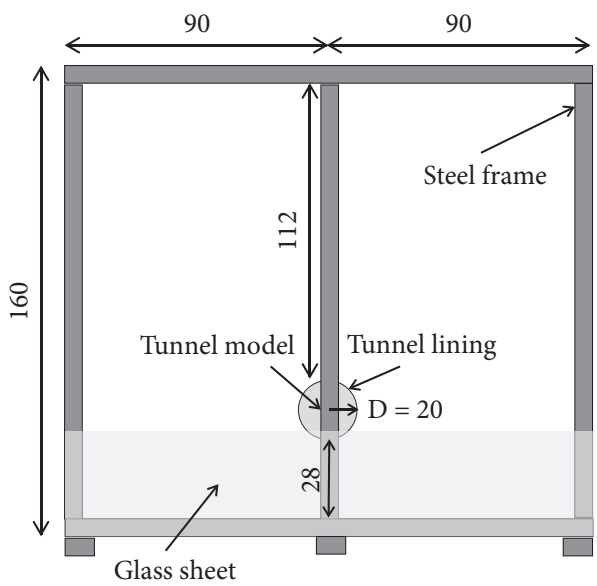

(b)

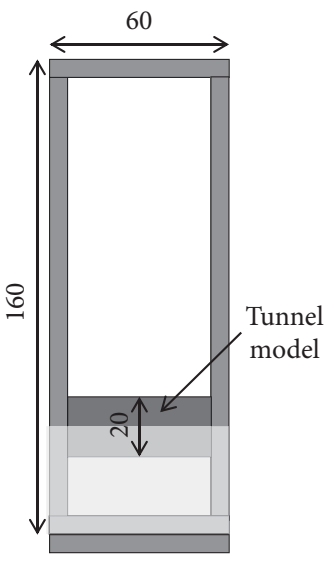

(c)

Figure 4: Model test chamber (unit: $\mathrm{cm}$ ). (a) Actual image. (b) Front view. (c) Side view.

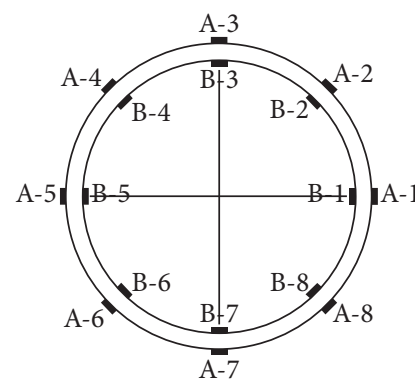

(a)

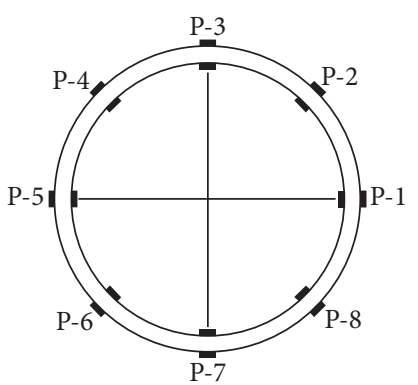

(b)

Figure 5: (a) Arrangement of strain gauges. (b) Arrangement of earth pressure boxes. 

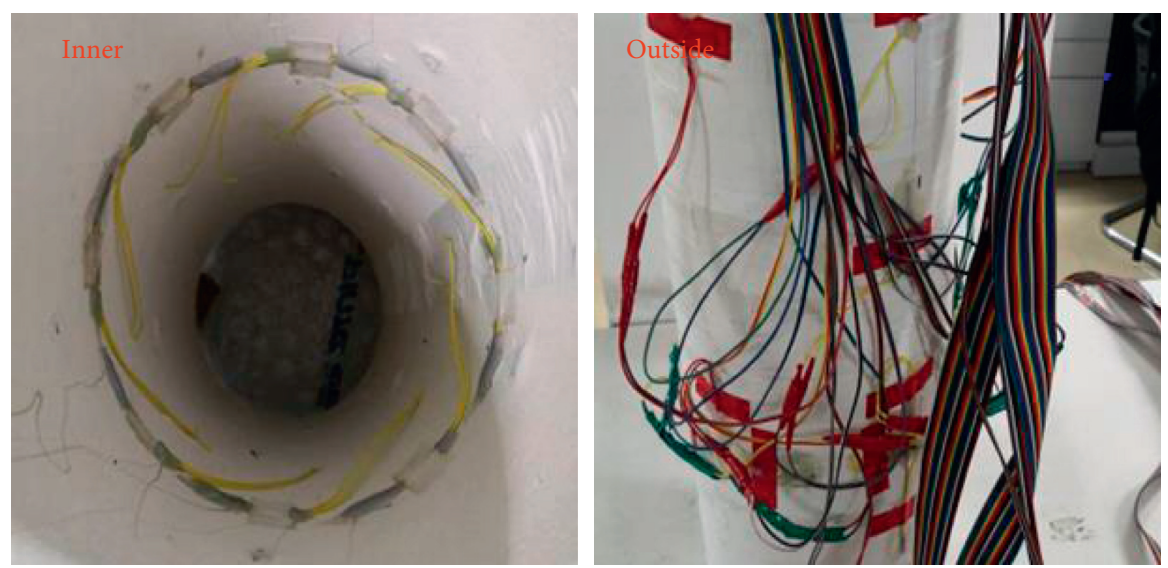

Figure 6: Tunnel lining monitoring system.

Step 4. The strain gauges and earth pressure boxes are installed on the prepared tunnel, and the operation monitoring system is debugged to ensure that the first monitoring data is recorded and saved once it has been corrected.

Step 5. The tunnel is placed in the preset position and is carefully pressed so that its bottom makes contact with the stratum tightly, and then it is filled with the similar stratum soil layer by layer by the filling and compaction method. The layer thickness should be controlled at $15-20 \mathrm{~cm}$ appropriately. The soil layer on the tunnel is filled to the design height, and finally plain fill and miscellaneous fill soil layers are added.

Step 6. The original data should be collected when the tunnel model is placed in the stratum for the first time. At this time, it is considered that the tunnel model is in the undisturbed state. That is, any subsequent changes of the monitored data are caused by the overlying load. In principle, single acquisition and time interval acquisition are used for data acquisition in parallel. Data is collected and recorded every hour, and monitoring is considered complete, and data is saved $3 \mathrm{~h}$ after data values become stable.

\section{Model Test Results}

The model used in this test is a uniform column gypsum model. From the strain, axial force, and bending moment obtained in the test, the overall distribution trend of the internal force is relatively symmetrical, but the data has different degrees of deviation, so it exhibits asymmetric differences (see Figure 7).

3.1. Bending Moment. For the bending moment (see Figure $7(\mathrm{~b})$ ), the strains are $352 \mu \varepsilon$ and $285 \mu \varepsilon$ when measured at P3 and P7, so the positive bending moments of the two measuring points are $92.4 \mathrm{kN} \cdot \mathrm{m}$ and $74.81 \mathrm{kN} \cdot \mathrm{m}$, respectively. There is a small difference between the data of measuring points 2 and 4 and between the data of measuring points 6 and 8. The strains at $\mathrm{P} 2$ and $\mathrm{P} 4$ are $-121 \mu \varepsilon$ and $-125 \mu \varepsilon$, respectively, and when converted into bending moments are $-31.76 \mathrm{kN} \cdot \mathrm{m}$ and $-32.81 \mathrm{kN} \cdot \mathrm{m}$, respectively. The difference between the two is $4 \%$, and that between measuring points 6 and 8 is $2 \%$. However, the strains and values of P1 and P5 are relatively scattered $(-135 \mu \varepsilon$ and $-152 \mu \varepsilon$, respectively). The corresponding bending moment values are $-35.44 \mathrm{kN} \cdot \mathrm{m}$ and $-39.9 \mathrm{kN} \cdot \mathrm{m}$, respectively, indicating a $12 \%$ difference. It can thus be seen that the overall distribution of the bending moment is not uniform. The cross distribution of the positive and negative bending moments causes the internal and external surfaces of the lining to bear different degrees of tension, which is unfavorable for concrete structures. Based on the overall distribution of bending moments, the deformation trend of the lining is that the dome and base are characterized by the outer surface being pressed, while the inner surface is being pulled and is being recessed inward. The force is gradually transitioned from the base to the side of the arch to the outside, and the upper half of the arch experiences the highest stress. The horizontal arched waist on both sides is characterized by the inner side being tensioned and protruding outward.

3.2. Axial Force. For the axial force (see Figure $7(\mathrm{c})$ ), the strain has the most extreme value of $-243 \mu \varepsilon$ at P2; that is, the extreme point of the axial force occurs at P2, while a corresponding $-241 \mu \varepsilon$ value is measured at $\mathrm{P} 4$. The axial force difference between the two points is not large $(-1275.75 \mathrm{kN}$ versus $-1265.25 \mathrm{kN})$. P6 and P8 are similarly distributed $(-960.75 \mathrm{kN}$ versus $-966 \mathrm{kN})$. In contrast, the strain difference between P1 and P5 is notable $(-231 \mu \varepsilon$ versus $-220 \mu \varepsilon$ ), and the axial force values are $-1212.75 \mathrm{kN}$ and $-1155 \mathrm{kN}$, respectively, corresponding to a relative error of $5 \%$. The maximum positive bending moment corresponds to the strain point at P3 and the value is $-182 \mu \varepsilon$; that is, the axial moment corresponding to the maximum positive bending moment monitored is $-987 \mathrm{kN}$, and the second largest bending moment value is the axial force at the base measuring point $(-1065.75 \mathrm{kN})$, which is obviously greater than the axial force at the maximum point of the bending moment. Therefore, the distributions of the bending moment and axial force are not positively correlated. It is advantageous for a concrete lining that the entire distribution of the axial force is negative; that is, the lining is in a compression state. 


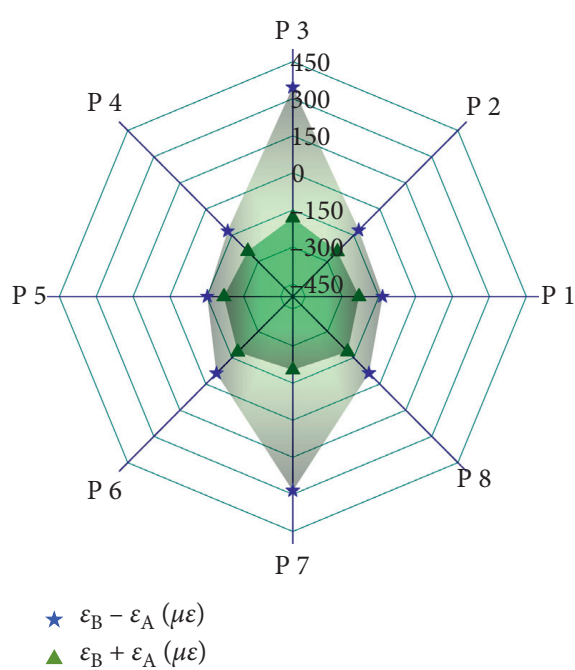

(a)

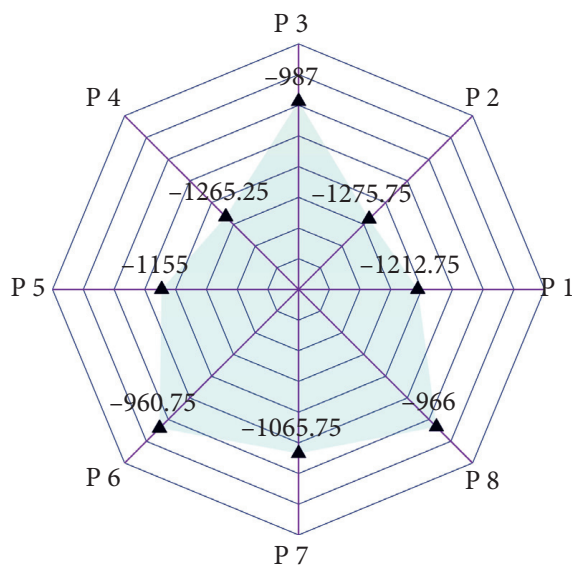

- Axial force $(\mathrm{kN})$

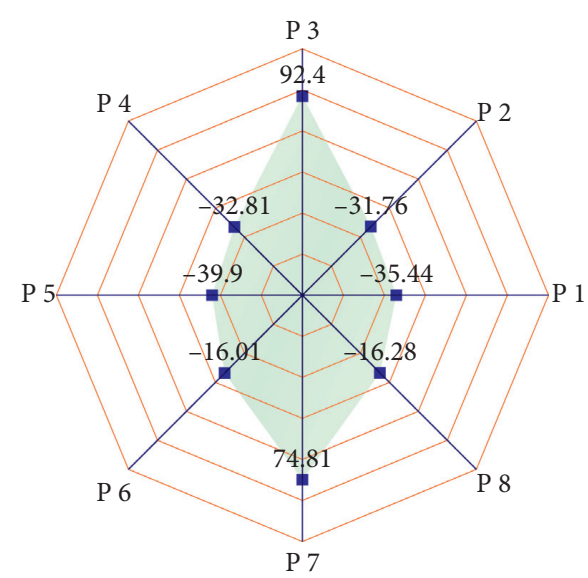

- Bending moment $(\mathrm{kN} \cdot \mathrm{m})$

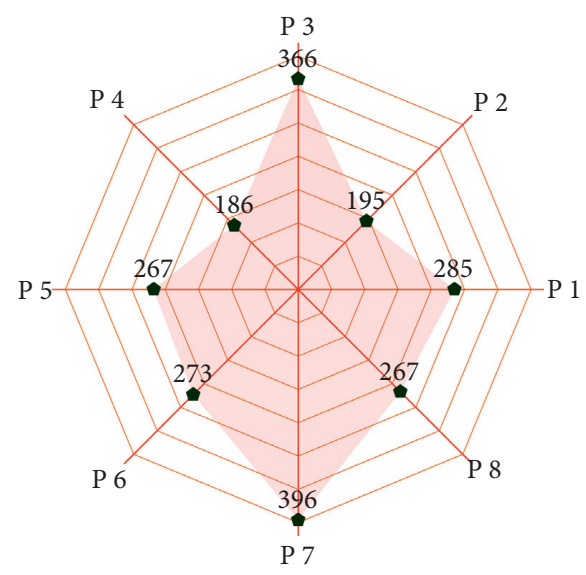

- Pressure (kPa)

(d)

Figure 7: Test results. (a) Sum and difference in strain. (b) Moment. (c) Axial force. (d) Earth pressure.

3.3. Earth Pressure. For the earth pressure (see Figure 7(d)), the values collected by the earth pressure boxes in this test are actually the sum of the water and earth pressure of the artificial clay configured, which also corresponds to the calculation method for water and soil in the sticky soil layer. During the test, the earth pressure collection interval is $1 \mathrm{~h}$, and the final stable data are used as the reference. It can be seen that the distribution of earth pressure is symmetrical, but the deviation of the symmetrical position ranges between 5 and $7 \%$. The data without micro strain gauge monitoring is stable. From the earth pressure values, the earth pressure of the dome monitoring point is $366 \mathrm{kPa}$, which is slightly lower than the theoretical gravity of the similar soil layer, and the maximum value is $396 \mathrm{kPa}$, located at the base. The measuring points on both sides show different characteristics from the static earth pressure method. For example, the earth pressure of $285 \mathrm{kPa}$ at P1 is larger than the earth pressure of $267 \mathrm{kPa}$ at $\mathrm{P} 8$. This is because the artificial filling is similarly laminated with limited solidity. During the filling process, the soil on both sides of the tunnel will gradually squeeze the tunnel model and reflect the state of the active earth pressure. The distribution of earth pressure at this measured point is generally symmetrically distributed, but the distribution of earth pressure in the right half is slightly larger than that in the left half. Analysis for the reasons first indicates that because the volume of a micro earth pressure box is several times that of a micro strain gauge, the monitoring accuracy will be reduced to varying degrees. Second, the strain gauges are laid flat on the outer surface of the lining with special $\mathrm{AB}$ glue, so their entire body attaches evenly and smoothly to the wall. In contrast, the earth pressure boxes are raised on the lining surface and, to some extent, are displaced by the extrusion of the soil body, causing deviations in the built-in strain sensing elements. In addition, the clay has a relatively high water content, which may be stirred and vibrated during the filling process of the model soil, resulting in local agglomeration, which should not be ignored and should be avoided as much as possible. 


\section{Back Analysis of Load Action Mode}

Referring to the previous experience of studies focused on load distribution patterns and the geologic conditions of the Foshan area [40-43], four load distribution patterns are assumed: (1) vertical load distribution and horizontal load linear distribution, (2) vertical load distribution and horizontal load parabolic distribution, (3) vertical load parabolic distribution and horizontal load linear distribution, and (4) vertical and horizontal load parabolic distribution. These distributions are used for subsequent analysis and calculation.

The specific hypothesis of a finite element calculation is that, for the vertical uniform load to be assumed as the total weight of the overlying soil, the load of the vertical parabolic distribution is first assumed to be a quadratic parabolic distribution and then is calculated according to the total soil weight plus the weight at both ends. The friction of the sliding surface determines the specific distribution function. For a horizontally linearly distributed load, the specific value can be determined by the active earth pressure calculation method. For a horizontal parabolic distribution, the function is assumed to be a quadratic function and is calculated based on the active earth pressure at the dome and at the base and near the arch waist. The magnitude of the static earth pressure further determines the load distribution function, so the parabolic shape is mainly affected by soil weight, Poisson's ratio, and the internal friction angle.

4.1. Model Establishment. This paper intends to carry out back analyses based on the soil-soil calculation and loadstructure model. In the calculation process of the analysis, the finite element software ABAQUS is used to simulate the tunnel segment using the beam element B21, which is reduced on the basis of C50 concrete stiffness ( $35 \mathrm{GPa}$ ), and $\eta=0.8$ [44]. The foundation resistance is achieved by setting the spring unit as Spring A. The boundary conditions impose two-degrees-of-freedom constraints on the point where the spring is not in contact with the lining and a single-degree-of-freedom constraint on the horizontal and vertical symmetry points of the lining (lining: $\gamma=26 \mathrm{kN} / \mathrm{m}^{3}$; then $g=\pi \cdot \gamma \cdot t=24.49 \mathrm{kPa}$ ).

In the calculation and comparative analysis of the test data and finite metadata, this paper will derive the model internal forces corresponding to the locations of the model test internal force monitoring system sensors from the ABAQUS finite element software for comparative analysis. That is, we take the horizontal right arch waist as the starting point of the azimuth and rotate counterclockwise to obtain the complete azimuth in the order 1 (1), 2 (19), 3 (37), 4 (55), 5 (73), 6 (91), 7 (109), and 8 (127), where the numbers in parentheses are the corresponding node numbers in the finite element calculation (see Figure 8).

In fact, the lining segment is subjected to bending moment, axial force, and shearing force, which is not a decisive factor in segment design because of its small value and influence. The calculation result of the axial force yields a negative value; that is, the axial direction of the segment is in a pressurized state, and the bending moment is a positive and negative cross-distribution. Using the finite element model, taking $200 \mathrm{kPa}, 250 \mathrm{kPa}, 300 \mathrm{kPa}, 325 \mathrm{kPa}, 350 \mathrm{kPa}$, $375 \mathrm{kPa}, 400 \mathrm{kPa}, 425 \mathrm{kPa}, 450 \mathrm{kPa}$, and $500 \mathrm{kPa}$ as the arch load, respectively, the internal force of the lining under the action of various loads is calculated and the load internal force curve for the eight measuring points is drawn, which can further summarize the change rule for the internal force as the load level increases. Then, the test monitoring data is substituted into the load-internal force curve and the corresponding load values are solved for. Finally, according to the magnitude of each back-calculated load, the final value is comprehensively analyzed, and the results are substituted into the finite element model to calculate the most suitable load distribution pattern.

4.2. Model Back Analysis. In this paper, load mode I is taken as an example for analysis and the remaining three modes are only analyzed in the form of a results chart. According to the above content, apply the load step by step in mode I to obtain the corresponding internal force nephogram and then select the representative part to display, as shown in Figure 9.

It can be seen from Figures 9 and 10 that the axial force always exhibits a negative value; that is, the lining is under pressure. The bending moment changes of the lining show different degrees of variation according to the different parts. Measuring points 1, 2, 3, and 4 always exhibit negative values; that is, they are in the inner pressure state, and measuring points 3 and 7 (vault and base) always exhibit a positive value such that the inside of the segment is being pulled. Points 6 and 8 (lower arch waist) gradually change from $7.8 \mathrm{kN}$ to $-11.22 \mathrm{kN}$ with increasing arch load, which gradually changes from inner tension to outer tension. The maximum positive bending moment of the dome and the corresponding axial forces are $141.96 \mathrm{kN}$ and $-1228.2 \mathrm{kN}$, respectively. The finite element calculation uses a uniform cylinder, so the internal force of the tunnel is symmetrical under load.

Compared with the modified conventional coefficient method, the internal force distribution law is basically the same. The maximum positive bending moment appears in the vault, and the maximum negative bending moment appears in the arch waist; that is, the momentum measured by model unit node 10 is at an angle of approximately $30^{\circ}$ with respect to the horizontal direction. The maximum value of the axial force appears on both sides of the arch waist, and the load distribution pattern on the lining in the eight directions of bending moment and axial force is shown in Figure 10.

In the previous content, the bending moments and axial forces of eight measuring points in the model test have been measured. According to back analysis (as shown in Figure 1), next, through the comparison of the load internal force curve in different directions with the bending moment and axial force collected by the test monitoring, the load values of the monitoring data under the load distribution for mode I are comprehensively back-analyzed, as shown in Figure 11. Here, only the back-analysis figures of measuring points 1, 2, 3 , and 7 are listed (the tunnel has uniform symmetry).

As shown in Figure 11, the bending moment and axial force of the same monitoring part have different degrees of 


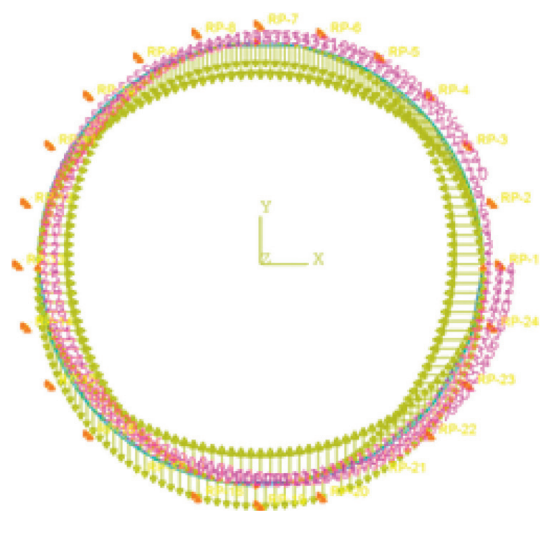

(a)

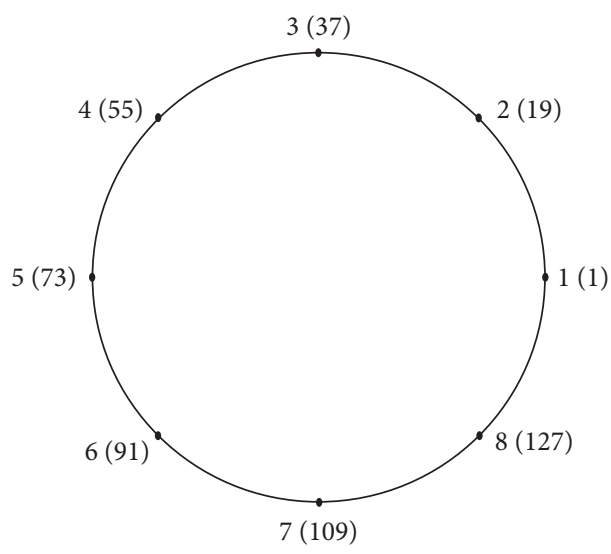

(b)

FIGURE 8: Forward analysis calculation model. (a) Finite element model. (b) Layout of measuring points and node numbers.
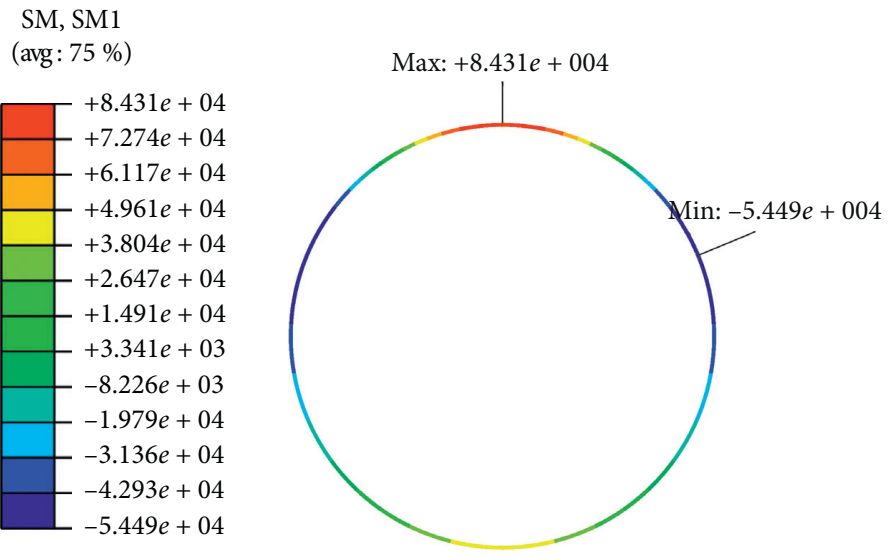

Max: $+8.431 e+04$

Unit: SUIDAO - 1.36

Node: 37

Min: $-5.449 e+04$

Unit: SUIDAO - 1.9

Node: 10

(a)
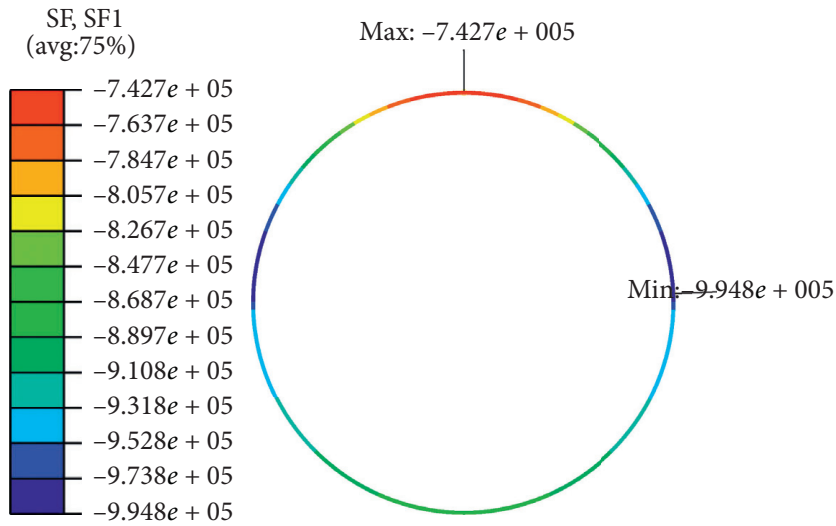

Max: $-7.427 e+05$

Unit: SUIDAO-1.36

Node: 37

Min: $-9.948 e+05$

Unit: SUIDAO-1.1

Node: 2

(b)

Figure 9: Continued. 
SM, SM1

(avg: 75\%)

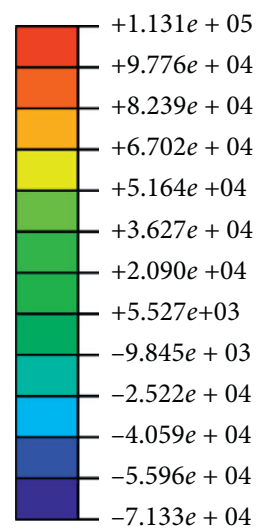

Max: $+1.131 e+05$

Unit: SUIDAO - 1.36

Node : 37

Min: $-7.133 e+04$

Unit: SUIDAO - 1.9

Node: 10

$$
\text { SF, SF1 }
$$$$
\text { (avg: 75\%) }
$$

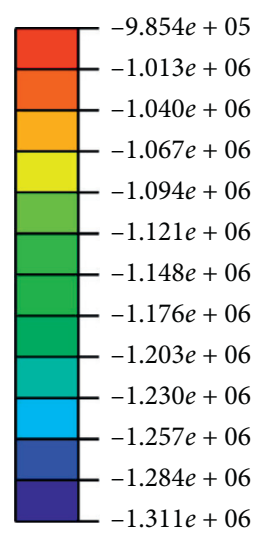

Max: $-9.854 e+05$

Unit: SUIDAO-1.36

Node: 37

Min: $-1.311 e+06$

Unit: SUIDAO-1.1

Node: 2

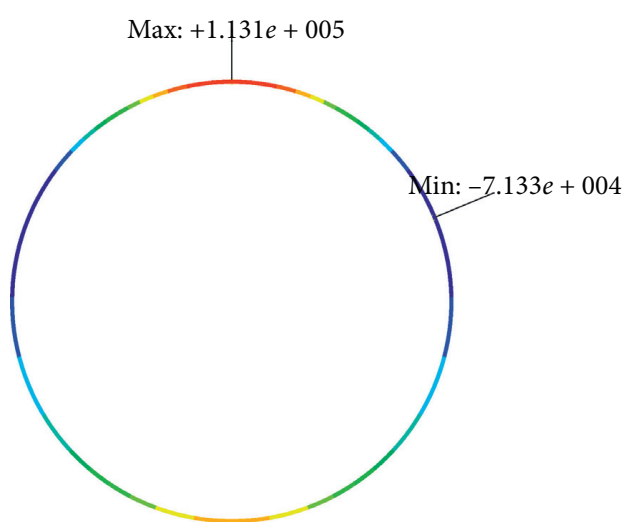

(c)

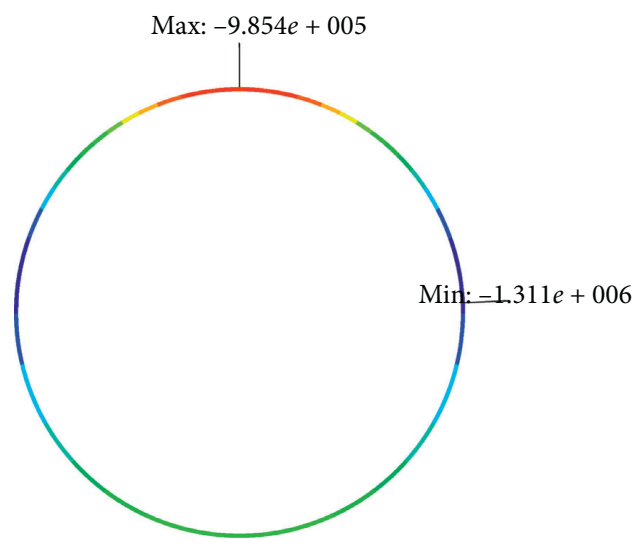

(d)

Figure 9: Bending moment and axial diagrams for load mode I. (a) Bending moment diagram under 300kPa (N.m). (b) Axial force diagram under $300 \mathrm{kPa}(\mathrm{N})$. (c) Bending moment diagram under $400 \mathrm{kPa}(\mathrm{N} \cdot \mathrm{m})$. (d) Axial force diagram under $400 \mathrm{kPa}(\mathrm{N})$.

difference in magnitude for the inverse analysis. The load calculated by the bending moment is inversely calculated from the other measuring points at the individual measuring points. In some cases, the value comparison is too large, such as for point 7 . Similarly, the load calculated by the axial force of point 2 is notably different from the other measuring points. According to the back analysis of bending moments, the loads are $285 \mathrm{kPa}, 341 \mathrm{kPa}, 324 \mathrm{kPa}, 351 \mathrm{kPa}, 321 \mathrm{kPa}$, and $411 \mathrm{kPa}$ (the monitoring data of measuring points 6 and 8 are not in the range of the back calculation data), and the loads based on axial force are $375 \mathrm{kPa}, 429 \mathrm{kPa}, 385 \mathrm{kPa}, 435 \mathrm{kPa}$, $354 \mathrm{kPa}, 319 \mathrm{kPa}, 379 \mathrm{kPa}$, and $322 \mathrm{kPa}$. Combined with the number of samples and load size, the linear regression equation is established, and the final value of load size under the distribution mode is $359 \mathrm{kPa}$ and so on. The final values of the load in the other three load modes are $380 \mathrm{kPa}$, $361 \mathrm{kPa}$, and $368 \mathrm{kPa}$, respectively. The sizes and distributions of the four load modes are shown in Figure 12. 


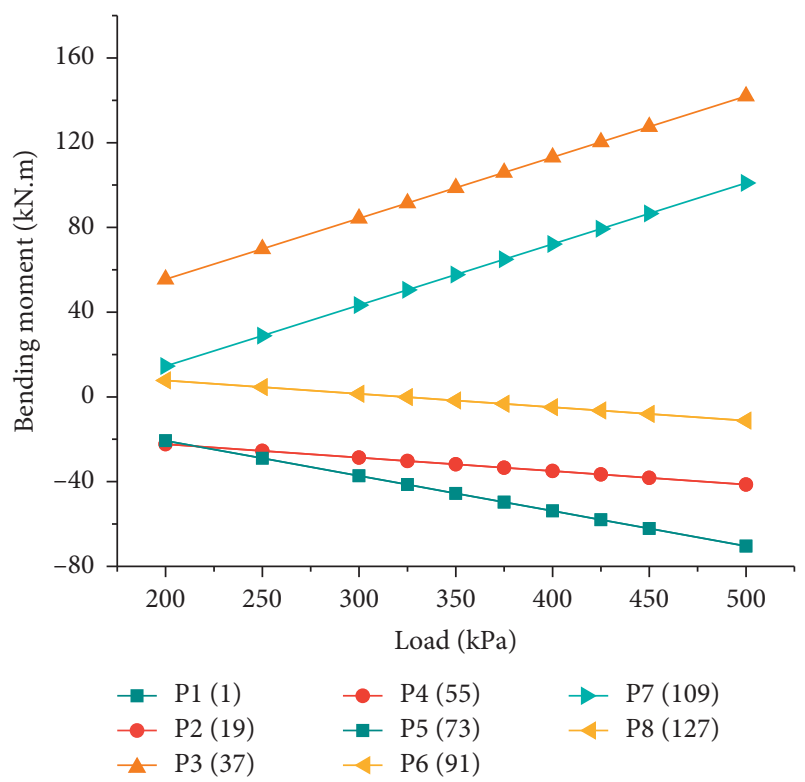

(a)

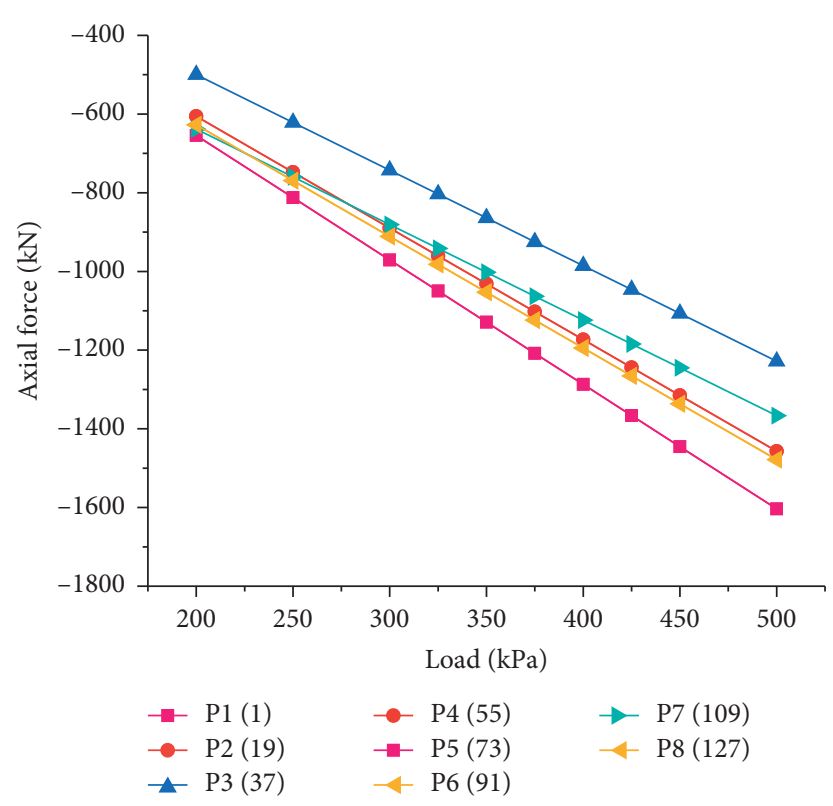

(b)

FIgURE 10: Internal force diagram of load mode I. (a) Load-moment diagram. (b) Load-axial diagram.

4.3. Results Analysis. In the foregoing, the load values of the four load modes have been inversely calculated, and the results are different. Therefore, the calculated internal force and the experimental monitoring value also have different degrees of deviation. The four load values are brought back to the corresponding calculation model one by one, and the bending moments and axial forces corresponding to the positions of the model test monitoring points are extracted, as shown in Table 3.

To observe the calculation effect of a single measuring point and the overall advantages and disadvantages of the finite element model, the relative error of the measuring point is shown in equation (4), and the overall error of the model is shown in equation (5). The results are shown in Table 3.

$$
\begin{aligned}
(\mathrm{RE})_{M} & =\left|\frac{\left|M_{i}\right|-\left|M_{j}\right|}{\left|M_{i}\right|}\right|, \\
(\mathrm{RE})_{N} & =\left|\frac{\left|N_{i}\right|-\left|N_{j}\right|}{\left|N_{i}\right|}\right|, \\
(E)_{M} & =\left|1-\frac{\sum_{j=1}^{n}\left|M_{j}\right|}{\sum_{i=1}^{n}\left|M_{i}\right|}\right|, \\
(E)_{N} & =\left|1-\frac{\sum_{j=1}^{n}\left|N_{j}\right|}{\sum_{i=1}^{n}\left|N_{i}\right|}\right|,
\end{aligned}
$$

where $M_{i}, N_{i}$ represent internal force value of test monitoring; $M_{j}, N_{j}$ represent calculation of internal force by finite element software; $n$ represents total number of measuring points.
According to the calculation of the relative error of the internal force calculated by the finite element method and the internal force monitored by the test, the moment calculated for load distribution mode 1 and distribution mode 3 is quite different at measuring points 6 and 8 , and the moment calculated by more than half of the points for the two modes is larger than the measured value. The similarity between the two distribution modes is that the horizontal load is assumed to be linearly distributed, which is primarily used in the soft clay area. In the case of ensuring the safety of the structure, the mode design calculation will cause some waste of materials because of the overestimate. In contrast, the bending moment deviation of mode 2 and mode 4 is lower, and the maximum value is less than $30 \%$. The overall distribution of the bending moment of mode 2 is slightly larger than the measured value and the extreme value of the bending moment calculated by mode 4 is less than the measured value, and other measuring points also show relatively uneven deviations.

The relative moment error between the axial force and the test monitoring value under the four load distribution modes is relatively small, but the large error of the load distribution for mode 2 and mode 3 at measuring points 6 and 2 is approximately $20 \%$. Furthermore, except for mode 2 , the error of the other three load modes at measuring points 2 and 4 is relatively large, between $16 \%$ and $20 \%$. The respective $(E)_{M}$ and $(E)_{N}$ model errors are $4.2 \%$ and $4.4 \%$, $1.3 \%$ and $2.3 \%, 5.5 \%$ and $7.8 \%$, and $5.4 \%$ and $6.4 \%$. In summary, the first three modes are conservative, and the material preparation will be unreasonable owing to the different degrees of deviation. Although the deviation of bending moment in the last mode is uneven, its bending moment error and axial force error fall in the middle range. 


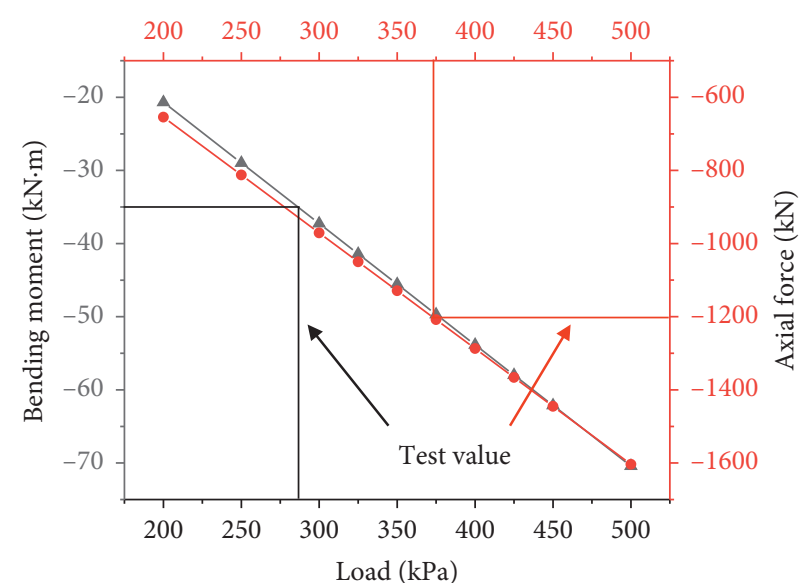

(P1)

$\neg$ Bending moment

$\rightarrow$ Axial force

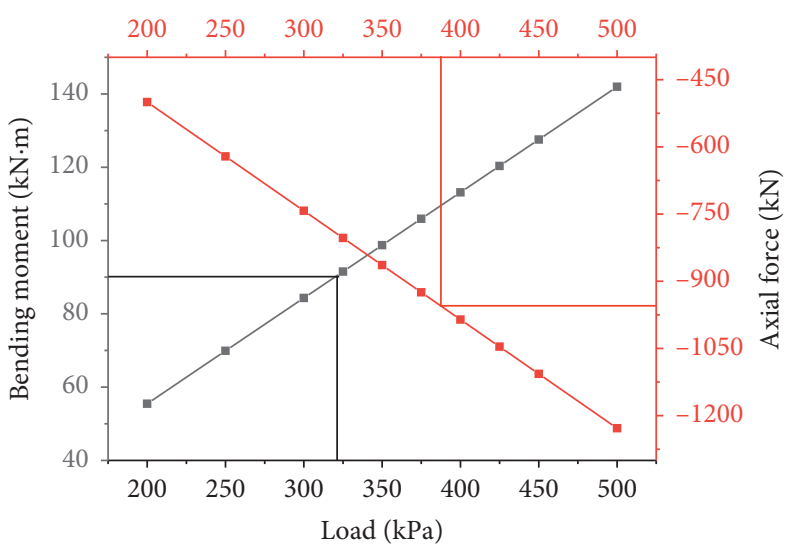

(P3)

$-\_$Bending moment

$\rightarrow$ Axial force

Figure 11: Comparison of the internal force curves between the test point values and the load mode.
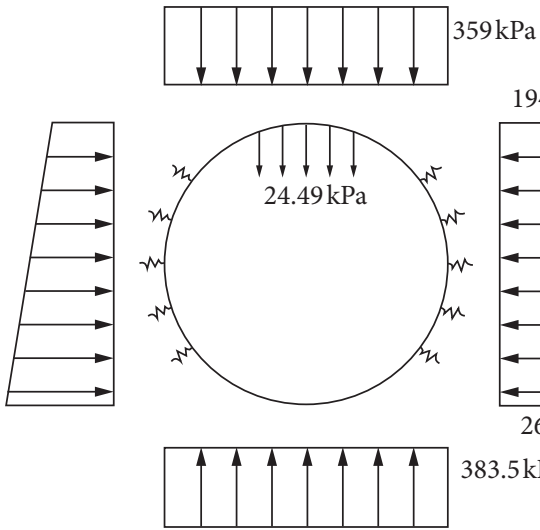

(a)

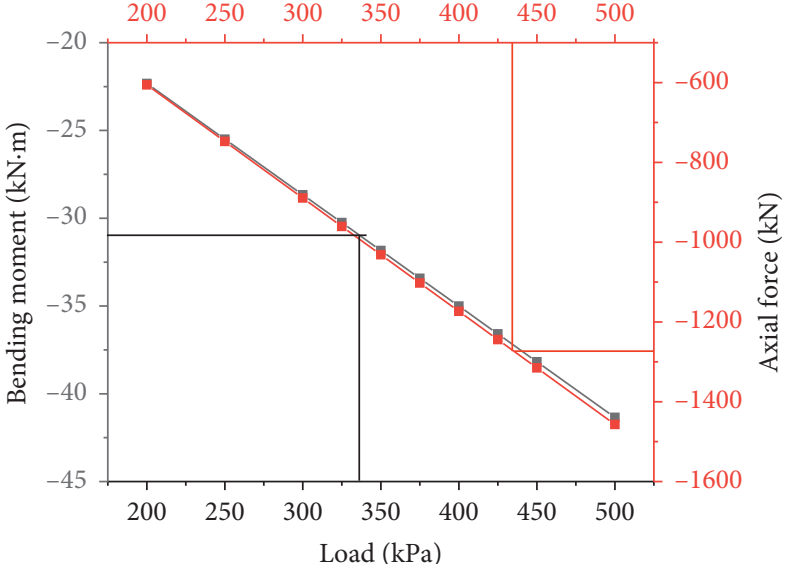

(P2)

$\rightarrow-$ Bending moment

$\rightarrow$ Axial force

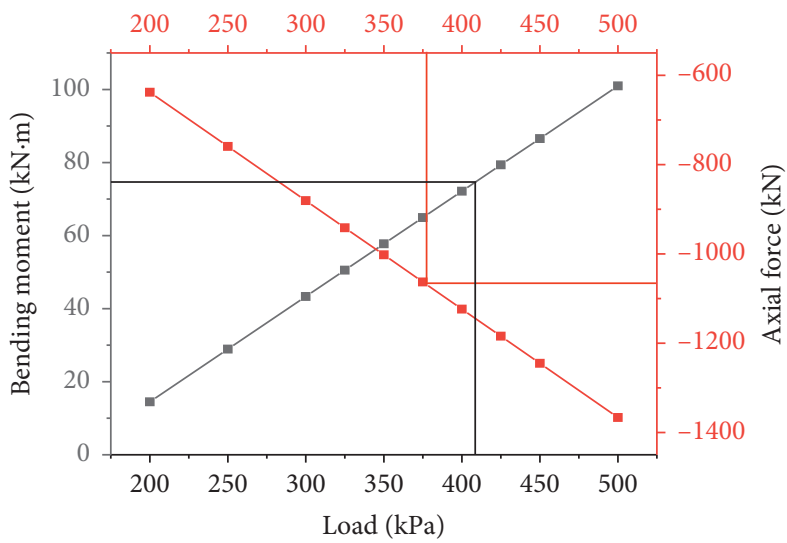

(P7)

$\rightarrow$ Axial force
$-\_-$Bending moment 


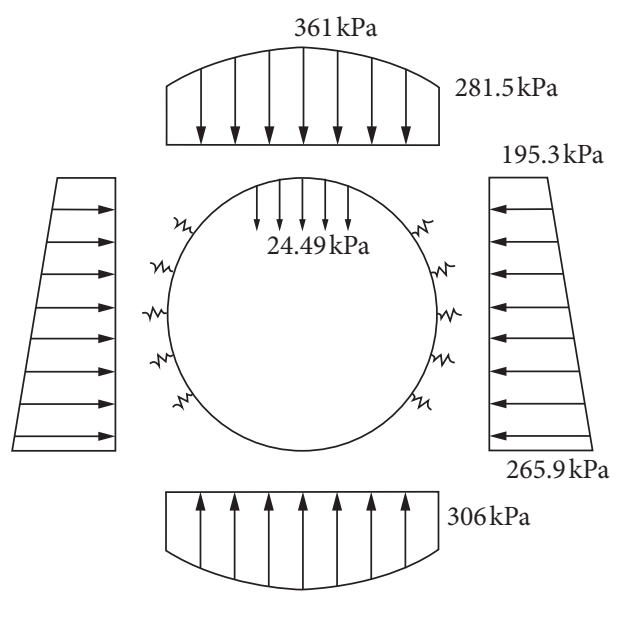

(c)

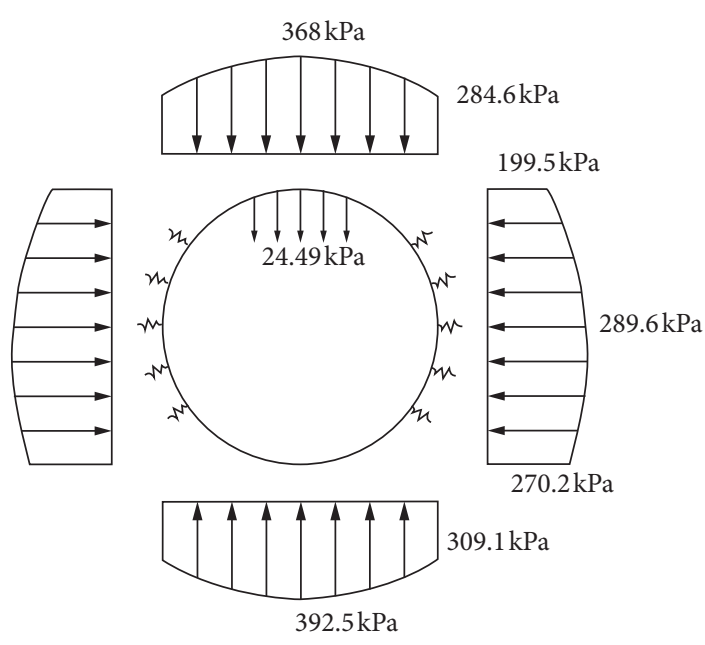

(d)

Figure 12: Back analysis of the four load distribution patterns. (a) Mode 1. (b) Mode 2. (c) Mode 3. (d) Mode 4.

TABLE 3: Comparison between measured values and finite element calculations.

\begin{tabular}{|c|c|c|c|c|c|c|c|c|c|c|c|c|}
\hline \multirow{3}{*}{ Position } & \multicolumn{12}{|c|}{ Relative error } \\
\hline & \multicolumn{3}{|c|}{ Load mode 1} & \multicolumn{3}{|c|}{ Load mode 2} & \multicolumn{3}{|c|}{ Load mode 3} & \multicolumn{3}{|c|}{ Load mode 4} \\
\hline & $\begin{array}{l}\text { Bending } \\
\text { moment }\end{array}$ & $\begin{array}{l}\text { Axial } \\
\text { force }\end{array}$ & Model & $\begin{array}{l}\text { Bending } \\
\text { moment }\end{array}$ & $\begin{array}{l}\text { Axial } \\
\text { force }\end{array}$ & Model & $\begin{array}{l}\text { Bending } \\
\text { moment }\end{array}$ & $\begin{array}{l}\text { Axial } \\
\text { force }\end{array}$ & Model & $\begin{array}{c}\text { Bending } \\
\text { moment }(\%)\end{array}$ & $\begin{array}{c}\text { Axial } \\
\text { force }(\%)\end{array}$ & Model \\
\hline $1(1)$ & 32.8 & 4.6 & \multirow{2}{*}{$(E)_{M}$} & 15.7 & 3.0 & \multirow{2}{*}{$(E)_{M}$} & 1.6 & 11.0 & \multirow{2}{*}{$(E)_{M}$} & 19.9 & 9.9 & \multirow{2}{*}{$(E)_{M}$} \\
\hline $2(19)$ & 2.0 & 17.2 & & 11.9 & 12.1 & & 17.9 & 19.4 & & 5.2 & 17.2 & \\
\hline $3(37)$ & 9.6 & 10.2 & \multirow{2}{*}{$4.2 \%$} & 2.2 & 1.7 & \multirow{2}{*}{$1.3 \%$} & 8.4 & 11.8 & \multirow{2}{*}{$5.5 \%$} & 3.1 & 7.9 & \multirow{2}{*}{$5.4 \%$} \\
\hline $4(55)$ & 1.2 & 16.5 & & 11.7 & 11.3 & & 14.1 & 18.7 & & 1.8 & 16.5 & \\
\hline $5(73)$ & 17.9 & 0.2 & \multirow[b]{2}{*}{$(E)_{N}$} & 2.8 & 8.2 & \multirow[b]{2}{*}{$(E)_{N}$} & 9.8 & 6.6 & \multirow[b]{2}{*}{$(E)_{N}$} & 28.8 & 5.4 & \multirow{2}{*}{$(E)_{N}$} \\
\hline $6(91)$ & 85.8 & 12.2 & & 14.5 & 21.6 & & 54.3 & 9.2 & & 19.4 & 10.9 & \\
\hline 7 (109) & 19.4 & 3.9 & \multirow{2}{*}{$4.4 \%$} & 0.6 & 1.9 & \multirow{2}{*}{$2.3 \%$} & 20.9 & 5.4 & \multirow{2}{*}{$7.8 \%$} & 6.6 & 8.4 & \multirow{2}{*}{$6.4 \%$} \\
\hline $8(127)$ & 86.0 & 11.6 & & 15.9 & 20.9 & & 55.0 & 8.7 & & 17.5 & 10.3 & \\
\hline
\end{tabular}

Therefore, the merits and demerits of each distribution mode should be further analyzed, and the errors of the bending moment and axial force should be comprehensively compared in the model analysis, rather than being judged based on a single element. Considering the evaluation of the results with the comprehensive error $E$ (equation (6)), the comprehensive errors of the four distribution modes are, respectively, $4.3 \%, 1.7 \%, 6.5 \%$, and $5.9 \%$. Therefore, the comprehensive error of a single measuring point and the overall error of the model indicate that load distribution mode 2 is more suitable for the lining load calculation in the Foshan area.

$$
E=\sqrt{(E)_{M} \cdot(E)_{N}}=\sqrt{1-\frac{\sum_{j=1}^{n} M_{j}}{\sum_{i=1}^{n}\left|M_{i}\right|}|\cdot| 1-\frac{\sum_{j=1}^{n} N_{j}}{\sum_{i=1}^{n}\left|N_{i}\right|} \mid} .
$$

\section{Conclusions}

In this paper, based on the typical water-rich soft clay layer present in the Foshan area, a 1:30 similarity model test is designed by using similarity theory, and the ABAQUS finite element software is used to carry out an inversion analysis. Four distribution modes of the external load of the tunnel lining of Foshan Metro Line 2 are compared and evaluated in detail, and the load action mode most suitable for the local area is determined, which provides a reference design scheme and solution methodology for similar projects. The mismatch problem between segment design and actual working conditions is solved by applying the proposed method. The main conclusions are as follows:

(1) The monitoring data of similar model tests are distributed symmetrically as a whole. This is possible because the model tunnel can be regarded as a homogeneous thin-walled cylinder and a free edge ring. The bending moment distribution of the model lining shows that the overall deformation trend of the tunnel is Rugby-Ball-Like, and the data has discrete deviation phenomena. The test data show that the larger values of bending moment appear in the vault and base, while the measured value of the lower side of the arch waist is lower; therefore, it is necessary to carefully consider and provide reasonable reinforcement in the design. The maximum axial force is present in the lower left half of the arch 
waist, and the minimum axial force is present in the upper right half of the arch waist.

(2) The preparation of artificial clay to provide a similar test stratum is mainly based on commercial kaolin and bentonite, from which many groups of samples are made. After a large number of geotechnical tests, the proportions are constantly adjusted. Finally, when the proportions of kaolin, bentonite, loess, and river sand are $40 \%, 20 \%, 30 \%$, and $10 \%$, the physical and mechanical properties meet the requirements for similarity tests, which can be used to simulate the sea soft clay layer.

(3) In the calculation and analysis using ABAQUS based on the homogeneous ring model, the internal forces of the lining under the four modes are calculated by using the test monitoring earth pressure as the known load. The results indicate that when the distribution of the arch crown is consistent, the calculated internal force using the horizontal parabolic distribution is more consistent with the test value, and when the horizontal load is constant, the calculated internal force using the vertical parabolic distribution is less consistent.

(4) Taking the test monitoring bending moment and axial force as the known quantity, the specific load value is analyzed through the load internal force curve, and then the four load values are inserted back into the model to perform final, separate internal force calculations, and the bending moments and axial forces corresponding to the test monitoring positions of each loading mode are extracted. By using the comprehensive error function to analyze the consistency between the calculated value and the measured data, it is concluded that the calculation results of load mode 2 , namely, the uniform distribution of the arch top load and the parabolic distribution of the horizontal load, have the highest consistency with the test data and are therefore closest to the actual load distribution of the stratum, which provides the theoretical basis for the load calculation of the stratum.

\section{Data Availability}

The data used to support the findings of this study are included within the article.

\section{Conflicts of Interest}

The authors declare that they have no conflicts of interest.

\section{Acknowledgments}

The authors would like to acknowledge the financial support of the National Natural Science Foundation of China (Grant no. U1934213).

\section{References}

[1] W. C. Cheng, G. Li, A. Zhou, and J. Xu, "Rethinking the water leak incident of tunnel Luo09 to prepare for a challenging future," Advances in Civil Engineering, vol. 2019, Article ID 4695987, 11 pages, 2019.

[2] L. Dong, Z. Yang, Z. Wang, Y. Ding, and W. Qi, "Study on internal force of tunnel segment by considering the influence of joints," Advances in Materials Science and Engineering, vol. 2020, Article ID 1020732, 13 pages, 2020.

[3] X. J. Hao, Y. N. Wei, K. Yang et al., "Anisotropy of crack initiation strength and damage strength of coal reservoirs," Petroleum Exploration and Development, vol. 48, no. 1, pp. 243-255, 2021.

[4] B. Jiang, "Reconsideration on the development of urban rail transit industry in China under the belt and road initiative and the tide of globalization," Urban Rapid Rail Transit, vol. 31, no. 1, pp. 26-44, 2018.

[5] G. Zheng, T. Cui, X. Cheng et al., "Study of the collapse mechanism of shield tunnels due to the failure of segments in sandy ground," Engineering Failure Analysis, vol. 79, pp. 464-490, 2017.

[6] X. J. Hao, W. S. Du, Y. X. Zhao et al., "Dynamic tensile behaviour and crack propagation of coal under coupled staticdynamic loading," International Journal of Mining Science and Technology, vol. 30, no. 5, pp. 659-668, 2020.

[7] S. S. Jeong, Y. C. Han, Y. M. Kim, and D. Kim, "Evaluation of the NATM tunnel load on concrete lining using the ground lining interaction model," Ksce Journal of Civil Engineering, vol. 18, no. 2, pp. 672-682, 2014.

[8] K. K. Panthi and C. B. Basnet, "Evaluation of earthquake impact on magnitude of the minimum principal stress along a shotcrete lined pressure tunnel in Nepal," Journal of Rock Mechanics and Geotechnical Engineering, vol. 11, no. 5, pp. 920-934, 2019.

[9] H. Zhou, C. Zhang, Z. Li, D. Hu, and J. Hou, "Analysis of mechanical behavior of soft rocks and stability control in deep tunnels," Journal of Rock Mechanics and Geotechnical Engineering, vol. 6, no. 3, pp. 219-226, 2014.

[10] H. Katebi, A. H. Rezaei, M. Hajialilue-Bonab, and A. Tarifard, "Assessment the influence of ground stratification, tunnel and surface buildings specifications on shield tunnel lining loads (by FEM)," Tunnelling and Underground Space Technology, vol. 49 , pp. 67-78, 2015.

[11] W. C. Cheng, J. C. Ni, H. Huang, and S.-L. Shen, "The use of tunnelling parameters and spoil characteristics to assess soil types: a case study from alluvial deposits at a pipejacking project site," Bulletin of Engineering Geology and the Environment, vol. 78, no. 4, pp. 2933-2942, 2019.

[12] E. Fathalla and E. Farouk, "Interaction of tunnel linings and soft ground," Tunneling and Underground Space Technology, vol. 7, pp. 33-43, 1992.

[13] X. Y. Hou, "Elasto-plastic theory of the underground circular structure," Journal of Tongji University, vol. 4, pp. 50-62, 1982.

[14] C. Lin, S. Wu, and T. Xia, "Design of shield tunnel lining taking fluctuations of river stage into account," Tunnelling \& Underground Space Technology Incorporating Trenchless Technology Research, vol. 45, pp. 107-127, 2015.

[15] G. F. Liu, Q. Jiang, G. L. Feng, D.-F. Chen, B.-R. Chen, and Z.-N. Zhao, "Microseismicity-based method for the dynamic estimation of the potential rockburst scale duringtunnel excavation," Bulletin of Engineering Geology and the Environment, vol. 80, no. 4, pp. 1-24, 2021. 
[16] K. Wu and Z. S. Shao, "Study on the effect of flexible layer on support structures of tunnel excavated in viscoelastic rocks," Journal of Engineering Mechanics-ASCE, vol. 145, no. 10, 2019.

[17] I. M. Lee and S. Nam, "The study of seepage forces acting on the tunnelling and tunnel face in shallow tunnels," Tunneling and Underground Space Technology, vol. 16, pp. 31-40, 2001.

[18] Z. Z. Yang, Y. Q. Wang, L. Song, and X. Wang, "Theoretical study on internal forces of primary support of tunnel by considering time effect," Advances in Materials Science and Engineering, vol. 2020, Article ID 4254178, 8 pages, 2020.

[19] K. R. Hong, Innovation and Practice of Underwater Tunnel Construction by Drilling and Blasting Method, Vol. 6, China Railway Publishing House, Beijing, China, 2015.

[20] A. Bobet, "Effect of pore water pressure on tunnel support during static and seismic loading," Tunnelling and Underground Space Technology, vol. 18, no. 4, pp. 377-393, 2003.

[21] B. Kumar and J. P. Sahoo, "Support pressure for circular tunnels in two layered undrained clay," Journal of Rock Mechanics and Geotechnical Engineering, vol. 12, no. 1, pp. 135-148, 2020.

[22] S. C. Gu, P. Zhou, W. Sun, C. Hu, Z. Li, and C. Wang, "Study on the stability of surrounding rock of underground circular cavern based on the anchor reinforcement effect," Advances in Civil Engineering, vol. 2018, Article ID 4185070, 18 pages, 2018.

[23] I. M. Lee, K. J. Park, and S. W. Nam, "Analysis of an underwater tunnel with consideration of seepage force," Tunnels and Metropolises, vol. 15, pp. 315-319, 1998.

[24] J. F. Lou, F. Q. Gao, J. H. Yang et al., "Characteristics of evolution of mining-induced stress field in the longwall panel: insights from physical modeling," International Journal of Coal Science and Technology, no. 1, 2021.

[25] J. H. Shin, D. M. Potts, and L. Zdravkovic, "The effect of porewater pressure on NATM tunnel linings in decomposed granite soil," Canadian Geotechnical Journal, vol. 42, no. 6, pp. 1585-1599, 2005.

[26] X. Wu, Y. Jiang, K. Masaya, T. Taniguchi, and T. Yamota, "Study on the correlation of vibration properties and crack index in the health assessment of tunnel lining," Shock and Vibration, vol. 2017, Article ID 5497457, 9 pages, 2017.

[27] P. Chaipanna and P. Jongpradist, "3D response analysis of a shield tunnel segmental lining during construction and a parametric study using the ground-spring model," Tunnelling and Underground Space Technology, vol. 90, pp. 369-382, 2019.

[28] C. B. Basnet and K. K. Panthi, "Roughness evaluation in shotcrete-lined water tunnels with invert concrete based on cases from Nepal," Journal of Rock Mechanics and Geotechnical Engineering, vol. 10, no. 1, pp. 42-59, 2018.

[29] Z. D. Ding, J. Fu, X. Q. Li, and X. Li, "Mechanical behavior and its influencing factors on engineered cementitious composite linings," Advances in Materials Science and Engineering, vol. 2019, Article ID 3979741, 15 pages, 2019.

[30] Y. Q. Wang, H. T. Chang, and J. Wang, "Countermeasures to treat collapse during the construction of road tunnel in fault zone: a case study from the yezhuping tunnel in south qinling," Environmental Earth Sciences, vol. 75, no. 15, pp. 464-480, 2019.

[31] H. Mashimo and T. Ishimura, "Evaluation of the load on shield tunnel lining in gravel," Tunneling and Underground Space Technology, vol. 18, no. 2-3, pp. 233-241, 2003.

[32] W. J. Zhang, J. H. Wang, M. M. Jin, and A. Koizumi, "Numerical analysis of DRC segment under inner water pressure based on full-scale test verification for shield tunnel,"
Tunnelling and Underground Space Technology, vol. 56, pp. 157-167, 2016.

[33] X. L. Weng, Y. F. Sun, and Y. W. Zhang, "Physical modeling of wetting-induced collapse of shield tunneling in loess strata," Tunneling and Underground Space Technology, vol. 90, pp. 208-219, 2019.

[34] T. H. Kim, T. Obara, and M. Yoshikawa, "Experimental study on the flow field behind a backward-facing step using a detonation-driven shock tunnel," Shock Waves, vol. 15, no. 1, pp. 1-12, 2006.

[35] M. F. Lei, L. M. Peng, and C. H. Shi, "Model test to investigate the failure mechanisms and lining stress characteristics of shallow buried tunnels under unsymmetrical loading," Tunnelling and Underground Space Technology, vol. 46, pp. 64-75, 2015.

[36] M. A. Meguid, O. Saada, and M. A. Nunes, "Physical modeling of tunnels in soft ground: a review," Tunnelling and Underground Space Technology, vol. 23, no. 2, pp. 185-198, 2008.

[37] M. Panji, H. Koohsari, M. Adampira, H. Alielahi, and J. A. Marnani, "Stability analysis of shallow tunnels subjected to eccentric loads by a boundary element method," Journal of Rock Mechanics \& Geotechnical Engineering, vol. 8, no. 4, pp. 480-488, 2016.

[38] J. Zhou, J. Xu, and L. G. Yu, "Microscopic mechanism regarding permeability anisotropy of kaolin-montmorillonite mixed clays," Chinese Journal of Geotechnical Engineering, vol. 39, no. 1, pp. 1-9, 2018.

[39] Q. Xia, L. H. Jiang, and C. Zhong, "Effect of borax on the hydration process of FGD building gypsum and its mechanism analysis," New Building Material, vol. 10, pp. 5-8, 2011.

[40] Department of Geotechnical Engineering, University T, University P, et al., Analysis of the Different Load Models in the Lining Segments of Shield Tunnel, Geotechnical Engineering Technique, 2004.

[41] X. Liu, C. Zhang, C. Zhang, and Y. Yuan, "Ultimate loadcarrying capacity of the longitudinal joints in segmental tunnel linings: illustrated with the typical segment joints of the shanghai metro rapid transit system," Structural Concrete, vol. 18, no. 3, 2017.

[42] Working group No.2 and International Tunnelling Association, "International tunnelling association. guidelines for the design of shield tunnel lining," Tunnelling and Underground Space Technology, vol. 15, no. 3, pp. 303-331, 2000.

[43] X. C. Zhong and W. Zhu, "Back analysis of soil pressure acting on shield lining segment," Rock and Soil Mechanics, vol. 27, no. 10, pp. 1743-1748, 2006.

[44] T. Yu, "Numerical simulation and model test for effects of closed-spaced construction of subway shield tunnels," MS Thesis, Southwest Jiaotong University, Chengdu, China, 2005. 